\title{
Randomisation and resource allocation: a missed opportunity for evaluating health care and social interventions
}

Tami Toroyan, Ian Roberts and Ann Oakley Institute of Child Health, London and University of London Institute of Education, London

\begin{abstract}
Equipoise is widely regarded to be an essential prerequisite for the ethical conduct of a randomised controlled trial. There are some circumstances however, under which it is acceptable to conduct a randomised controlled trial (RCT) in the absence of equipoise. Limited access to the preferred intervention is one such circumstance. In this paper we present an example of a randomised trial in which access to the preferred intervention, preschool education, was severely limited by resource constraints. The ethical issues that arise when conducting randomised trials in health care are considered in the context of trials of social

interventions. In health, education and social welfare, effective interventions are frequently limited due to budgetary constraints. Explicit acknowledgement of the need to ration interventions, and the use of random allocation to do this even in the absence of equipoise, would facilitate learning more about the effects of these interventions.

(Fournal of Medical Ethics 2000;26:319-322)
\end{abstract}

Keywords: Randomised controlled trials; equipoise; rationing; preschool

The ethics of randomised controlled trials in health care

A number of ethical issues influence the design and conduct of randomised controlled trials, among which equipoise and informed consent are generally considered fundamental.

\section{EQUIPOISE}

Equipoise is defined as the point where a rational, informed person has no preference between two (or more) available treatments offered in a trial. Personal equipoise exists when an individual service provider or clinician has no preference or is uncertain about the overall benefit or harm offered by the treatment to his/her patient. Some trials address this issue by stipulating that individual clinicians who know, or have good reason to believe, that one arm of the treatment is superior may not ethically participate in the trial. ${ }^{2}$ Professional equipoise exists when within the profession as a whole, there is no consensus about which treatment is better. ${ }^{3}$ The ethical issues that arise when recruiting participants into a trial where there is professional equipoise but no personal equipoise and the conflict that occurs between social and individual obligations have been considered elsewhere. ${ }^{1-4}$ However, most ethics committees consider professional equipoise and personal equipoise, to be part of the "uncertainty principle", which is an essential prerequisite to conducting a randomised trial. ${ }^{2}$

\section{INFORMED CONSENT}

Informed consent is also considered to be fundamental to the ethical conduct of randomised controlled trials. Obtaining informed consent is a way of ensuring that research participants understand that professional equipoise or uncertainty exists with regard to treatment options, and so have realistic expectations of the outcome of their participation in the trial. ${ }^{5}$ In theory at least, participants who consent to take part in a trial should be in a state of equilibrium themselves about the risks and benefits of receiving each arm of the treatment in the trial. ${ }^{6}$ Informed consent also serves to ensure that research participants understand what their involvement in a trial means with regard to data collection. The importance of informed consent is deeply rooted in values surrounding personal autonomy. Apart from situations in which research participants are not competent to give informed consent, for example when they are unconscious, random allocation without consent is normally considered a breach of individual rights.

The effect of scarce resources on ethics of clinical trials

Randomisation has been used to allocate scarce resources in health care in situations where equipoise is lacking, in other words, where there was professional agreement that one treatment was preferable to another, or where individual clinicians themselves had preferences for a particular treatment. Historically, the innovation of randomisation arose from the need to combine scientific rigour in evaluation with a politically defensible method of rationing a scarce resource, in this case streptomycin for tuberculosis. ${ }^{7}$ Public demand for streptomycin exceeded its supply, and it was decided to make the drug available only to participants in a controlled trial.

Although equipoise and uncertainty are essential principles in guiding enrolment into randomised 
trials, in the context of scarce resources they are less appropriate criteria. Lilford and Jackson, in discussing exceptions to the requirement for personal equipoise, have argued that "randomisation in the absence of personal equipoise is permissible, even desirable, when access to treatment is in any case limited as a result of inadequate resources". ${ }^{1}$ They regard randomisation as an egalitarian method to allocate scarce resources. Today, however, it is only where the need to ration an intervention has been explicitly acknowledged that random allocation, in the absence of equipoise, becomes acceptable within the context of a trial. This has been accepted primarily in low income countries, where the need to ration is more openly acknowledged. ${ }^{8}$ For example, doctors in India who were unable to obtain enough anti-pseudomonas vaccine for burns patients used randomisation to allocate the limited supplies. $^{89}$

In high income countries, conducting a trial where there is no professional or personal equipoise has generally only been approved where new technologies are considered to require rigorous evaluation before becoming widely available. This is particularly relevant when there are concerns about the cost effectiveness of new technologies. ${ }^{1}$ Extracorporeal membrane oxygenation is an example of a new technology that was initially available only in the context of a trial, because of concerns about its cost effectiveness. ${ }^{10}$ Nevertheless, limiting access in this way is unusual, and equipoise and informed consent are widely regarded as ethical prerequisites for a clinical trial.

\section{Randomised trials without equipoise in other fields}

Although randomised trials of social interventions are uncommon in the UK, there is a long history of randomised trials, or social experiments, particularly in the US. In many of these trials, limited programme resources meant that random allocation was used as a fair method of rationing the intervention, with no ethical requirement for professional or individual equipoise in setting up the trial. For example, a training and support programme set up to assist single parents could not offer services to all eligible women. Lottery allocation was acceptable and even attractive to project administrators on equity grounds. ${ }^{11}$

\section{Case study: the Daycare Research Trial}

The Mapledene Early Years Centre is a new child care facility with an education focus in the London borough of Hackney, offering services to 70 children from the ages of six months to five years. The effects of this intervention on the health and welfare of families whose children have a place at the centre are being evaluated in a randomised trial. For this reason, childcare places at the centre are randomly allocated among eligible applicants. There is neither professional nor personal equipoise about the benefits of preschool education, and parents do not give informed consent for ran- dom allocation since this is an integral part of service provision. They do, however, give informed consent for participation in the trial, that is, for providing data. The trial has been approved by two ethics committees and is strongly endorsed by Hackney's Early Years Service.

PRESCHOOL INTERVENTION: THE NEED FOR A TRIAL

High quality preschool education is a public policy intervention with the potential to improve the health and welfare of disadvantaged children. Randomised controlled trials (RCTs) in the USA have shown that preschool education improves children's social and intellectual development and educational outcomes, and reduces the likelihood of school failure. ${ }^{12}$ Long term effects include increased employment, lower teenage pregnancy rates, higher socio-economic status and decreased criminal behaviour. North American economists have estimated that every dollar spent on preschool education saves seven dollars through reducing crime and welfare payments. ${ }^{13}$

However, despite research evidence in support of the benefits of preschool education, its potential effects on a number of important health and social outcomes remain unknown. For example, the effects of preschool education on children's injury rates, antibiotic resistance, and on maternal psychological health have yet to be quantified. In addition, although for some outcomes, such as child IQ, the positive effects of preschool education demonstrated in the North American research might be expected to apply within a UK context, other outcomes identified in the US studies cannot necessarily be generalised to other countries. For example, the effects of preschool education on maternal employment may vary with differences in labour market characteristics. As a result, there remains an incomplete picture with regards to quantifying the effects of preschool education provision. The important social policy question surrounding the public provision of preschool education in Britain concerns the extent to which the net benefits compare with the overall costs of providing it. Even if preschool education has established benefits, quantification of these benefits in specific social settings and the assessment of cost effectiveness remains an important research objective, and one addressed by this trial.

Britain has one of the lowest provisions of preschool education in Europe ${ }^{15}$ and there is a great unmet need for such services. ${ }^{16}$ However, it would be disingenuous to claim that there was professional uncertainty about benefits of high quality preschool education. The potential for preschool provision to reduce inequalities in health in the UK has been identified as a way of reducing inequalities in health, and a number of initiatives signal a shift in national policy that recognises the importance of high quality preschool education in children's early years experiences. ${ }^{14}$ 
THE ETHICS OF ALLOCATING PRESCHOOL EDUCATION The London Borough of Hackney is one of the most deprived in the country ${ }^{18}$ and this affects the demand for many of the services provided by the local authority. Preschool provision (usually offered as a place at a council-run or subsidised nursery) is a limited resource. The average waiting time for a nursery place is two years and in the most deprived parts of the borough, there are eight children applying for every place. ${ }^{19}$ As well as using lists that take into account a child's waiting time, the council maintains "urgent lists" for nursery places, giving priority to disadvantaged children, for example, those with learning disabilities or those from families on income support. However, with so many disadvantaged families applying for places, there are not even enough places for those on the urgent lists. Prioritising a child's need for a preschool place requires judgments to be made about the relative benefits of the intervention for different recipients. There is an inevitable problem in trying to prioritise when the effects of the intervention have not yet been fully quantified. Do children of single parents benefit more from a preschool place than those from two-parent families? Is a child with a learning disability more needy, and therefore more entitled to a place, than a child from a refugee family? Making such decisions in the absence of evidence of effectiveness and cost effectiveness of the intervention is therefore subjective and often inconsistent.

RANDOMLY ALLOCATING PRESCHOOL EDUCATION IN THE CONTEXT OF A TRIAL

Approached by the research team, the Mapledene Early Years Centre agreed to take part in a randomised controlled trial. Since the centre opened in 1999 random allocation has been the admissions policy. Insufficient supply of preschoo places presented an opportunity for the service to build a robust evaluation design into the planning of their new, high profile and innovative centre. Eligible families who apply to the centre are randomly allocated to receive a place or not. The policy allows a comparison of the health and welfare of families who receive a place at Mapledene and those that do not, within the context of a trial.

\section{The Daycare Research Trial}

LACK OF EQUIPOISE

Obstructing the conduct of an RCT of preschool education on the basis that there was no personal or professional equipoise around the effects of high quality preschool education would obscure the fact that most families in Hackney who want this intervention are denied it. Similarly, an individual service provider who feels that a family in Hackney would benefit from preschool provision may not be able to offer it to them. Random allocation represents an impartial and equitable means of distributing this scarce resource. As well as ensuring fairness in the allocation process, randomisation also relieves service providers of the responsibility of making subjective or contentious allocation

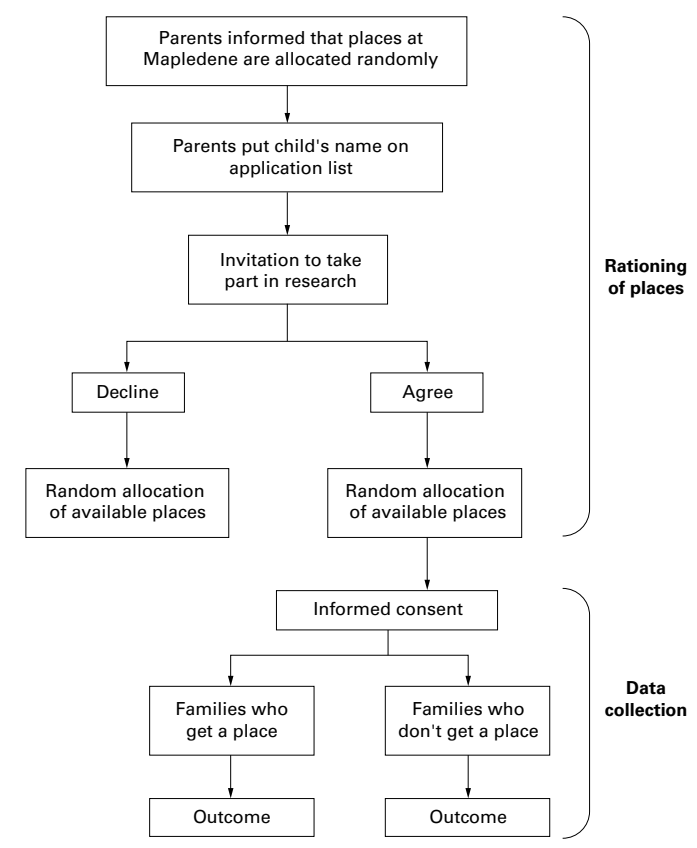

Figure 1: The Daycare Research Trial: recruitment of participants

decisions. The ability to carry out the Daycare Research Trial, in the absence of either professional or personal equipoise, rests upon the explicit acknowledgement by Hackney's Early Years Service that a limited number of daycare places inevitably means that rationing must take place.

\section{No informed consent for randomisation}

In most clinical trials the process of enrolling participants in a study involves obtaining consent for randomisation and data collection. In the Daycare Research Trial, informed consent is sought only for data collection and not for random allocation. Parents who decline to take part in the trial are still randomised to determine whether they get a place or not. The use of random allocation as an admissions policy results in a clear separation in this trial between randomisation and the data collection procedures of the trial, as shown in figure 1 .

\section{Conclusion}

We believe that the Hackney case study illustrates that conducting a randomised controlled trial in the absence of collective or personal equipoise is ethical. Clearly, this trial would not be feasible in countries where preschool education has higher priority on national agendas and demand for preschool education does not exceed its supply. However, given the current limited availability of preschool places in Hackney, random allocation is an ethical way of rationing the resource, whilst simultaneously allowing learning to take place about its effects. 
Within the health, educational and social sectors, resources are frequently scarce and many interventions are rationed, although normally not explicitly. We suggest that these situations present opportunities to use randomised trials to conduct rigorous evaluations of interventions, to quantify outcomes and to provide data on effectiveness and cost effectiveness that is needed for good policy decisionsdata which are often unavailable. Making use of these opportunities, however, requires acknowledging the inevitability of rationing.

\section{Acknowledgement}

The Daycare Research Study is funded by the Department of Health. It is a collaboration between the Institute of Child Health, the Institute of Education, the City and Hackney NHS Community Trust, the University of East Anglia and Hackney Early Years Service.

Tami Toroyan is Research Fellow in the Child Health Monitoring Unit, the Department of Epidemiology and Public Health, Institute of Child Health. Ian Roberts is Director of the Child Health Monitoring Unit. Ann Oakley is Director of the Social Science Research Unit, University of London Institute of Education, London.

\section{References}

1 Lilford RJ, Jackson J. Equipoise and the ethics of randomization. Fournal of the Royal Society of Medicine 1995; 88:552-9.

2 Collins R, Doll R, Peto R. In: Williams DJ, ed. Introducing new Collins R, Doll R, Peto R. In: Williams DJ, ed. Introducing new
treatments for cancer: practical, ethical and legal problems. treatments for cancer: practical, ethical

3 Freedman B. Equipoise and the ethics of clinical research. New England fournal of Medicine 1987;317:141-5.

4 Chard JA, Lilford RJ. The use of equipoise in clinical trials. Social Science and Medicine 1998;47:891-8.
5 Edwards SJ, Lilford R, Braunholtz DA, Jackson JC, Hewison J, Thornton J. Ethical issues in the design and conduct of randomised controlled trials. Health Technology Assessment 1998;2:15.

6 Yoshioka A. Use of randomisation in the Medical Research Council's clinical trial of streptomycin in pulmonary tuberculosis in the 1940s. British Medical fournal 1998;317:1220-3.

7 Alderson P. Equipoise as a means of managing uncertainty: personal, communal and proxy. Fournal of Medical Ethics 1996; 22:135-9.

8 Newman J, Rawlings L, Gertler P. Using randomised control designs in evaluating social sector programs in developing countries. The World Bank Research Observer 1994;9,2:181-201.

9 Lockwood M, Anscombe GE. Sins of omission? The non-treatment of controls in clinical trials. Aristotelian Society. 1983;57:207-22.

10 UK Collaborative Trials Group. UK collaborative randomised trial of neonatal extracorporeal membrane oxygenation. Lancet 1996;348:75-82.

11 Boruch RF. Randomized experiments for planning and evaluation: a practical guide. Applied social research methods evaluation: a practical guide. Applie
series, no 44. London: Sage, 1997 .

12 Zoritch B, Roberts I, Oakley A. The health and welfare effects of day-care: a systematic review of a randomised controlled trial. Social Science and Medicine 1998;47,3:317-27.

13 Barnett WS. Lives in the balance. Age- 27 benefit-cost analysis of the High/Scope Perry preschool program. Monographs of the High/Scope Educational Research Foundation, no 11. Ypislanti, Michigan: The High Scope Press, 1996.

14 HM Treasury. The modernisation of britain's tax and benefit system number 4. Tackling poverty and extending opportunity. tem number 4. Tackling pover

15 Kamerman SB. International perspectives on childcare policies and programs. Pediatrics 1993;91:248-52.

16 The Daycare Trust. Childcare gaps. London: The Daycare Trust, 1999.

17 Acheson D. Independent inquiry into inequalities of health report. London: Department of Health, 1998

18 Hargreaves S, Bardsley M, Barker M, Kenny D, Morgan D, Roberts I, et al. Child health in London. The health and social characteristics of London's children. The Health of Londoners characteristics of London's children. The Health of Londoners East London \& The City Health Authority, 1999.

19 The Early Years Development Partnership. Transforming early years. Hackney Early Years Development Plan, 1998-2001. London: London Borough of Hackney, 1998. 